\title{
Quality is in the eye of the stakeholders: what do professional subtitlers and viewers think about subtitling?
}

\author{
Agnieszka Szarkowska ${ }^{1}\left[\right.$ ] Jorge Díaz Cintas $^{2}\left[\right.$ ] $\cdot$ Olivia Gerber-Morón $^{3}[$
}

Published online: 6 July 2020

(c) The Author(s) 2020

\begin{abstract}
Quality is a rather slippery concept, and its assessment in subtitling can be a challenging task, as its appreciation can easily vary depending on the different stakeholders involved in the production and reception of subtitles. In this paper, we evaluate quality indicators in subtitling as perceived by professional subtitlers and viewers. After exploring the various subtitle parameters that can have an impact on the quality of the end product (such as line breaks, synchronisation, display rates), we present the results of two qualitative studies conducted with professional subtitlers and subtitle viewers with different audiovisual backgrounds. The results yield some similarities and discrepancies, particularly in the way in which the strategy of condensation is perceived by the two groups, and they also help delineate the subtitle parameters that should be taken into consideration in order to improve the creative process as well as the reception of subtitles.
\end{abstract}

Keywords Subtitling $\cdot$ Quality $\cdot$ Audiovisual translation $\cdot$ Viewers $\cdot$ Subtitlers $\cdot$ Subtitle display rates $\cdot$ Line breaks

\section{Introduction}

In today's digital society, audiovisual productions and subtitling are ubiquitous. Every day, we are exposed to subtitles in many different forms and formats, from commercial ones used on TV broadcasting, DVD distribution, cinema and video streaming platforms to amateur ones being popularised on the internet. Subtitling is not only valuable for audiences who are unfamiliar with the language of the original audio track, but is also appreciated by viewers who are deaf

Electronic supplementary material The online version of this article (https://doi.org/10.1007/s10209-020-00739-2) contains supplementary material, which is available to authorized users.

Agnieszka Szarkowska

a.szarkowska@uw.edu.pl

Jorge Díaz Cintas

j.diaz-cintas@ucl.ac.uk

Olivia Gerber-Morón

gerbermoron.olivia@gmail.com

1 Institute of Applied Linguistics, University of Warsaw, Dobra 55, 00-312 Warsaw, Poland

2 Centre for Translation Studies (CenTraS), University College London, Gower Street, London WC1E 6BT, UK

3 London, UK or hard-of-hearing or who require assistive services to be able to access audiovisual content.

Two main types of subtitling can be distinguished based on the linguistic transfer from the source to the target text: intralingual and interlingual [1]. Intralingual subtitling consists of a written rendition of spoken dialogues in the same language, for instance the English subtitles of an Englishlanguage programme; it has traditionally been classified under the umbrella of audiovisual media accessibility (MA) as the vast majority of intralingual subtitling is produced with deaf and hard-of-hearing viewers in mind. As such, it is generally referred to as 'subtitling for the deaf and the hard-of-hearing' (SDH) [2-4], though it is also known as 'closed captioning' in countries like the USA, Canada and Australia [5, 6]. Interlingual subtitling, on the other hand, is produced mainly with hearing audiences in mind, and it is not typically included under the umbrella of media accessibility, rather under that of audiovisual translation (AVT).

In this paper, however, we take a wider view of accessibility [7]. Following Díaz Cintas [8], we understand accessibility as 'making an audiovisual programme available to people that otherwise could not have access to it' (p. 4), irrespective of whether the barriers are sensory or linguistic. Such conceptualisation of the term 'media accessibility' encompasses both traditional types of AVT like dubbing, voiceover or interlingual subtitling, and more 'typical' media access 
services such as SDH, sign language interpreting or audio description for the blind and the partially sighted (AD). We contend that regardless of "whether the hurdle is a language or a sensorial barrier, the aim [...] is exactly the same: to facilitate the access to an otherwise hermetic source of information and entertainment' [8]. In this view, traditional types of AVT are seen from the perspective of media accessibility and 'accessibility becomes a common denominator that underpins these practices' [8].

In the last two decades or so, media accessibility has undergone a rapid evolution. Greco [7] distinguishes three shifts in the growth of MA: (1) from particularist to universalist accounts, (2) from a maker-centred to a user-centred approach and (3) from reactive to proactive approaches. The first shift denotes a change from understanding access in a narrow sense, i.e. focussing exclusively on specific viewer groups (known as 'ghettoisation'), towards a more inclusive and universal view, encompassing other viewer groups. Instead of being understood as a practice serving the deaf and the hard-ofhearing communities only, SDH can also be enjoyed by people with no hearing loss, who, for instance, use this service to learn languages. The second shift outlined by Greco [7] is particularly interesting for our study here: for many years, the belief that 'makers know best' has been dominant in AVT, assigning more prominence to the views of policymakers, professionals, researchers and other stakeholders in the industry than to those of the end users [9]. In recent years, however, this 'maker-user gap' [7, 10], where the makers and the users had traditionally been placed at the opposing ends of the AVT creation continuum, has started to change. In Greco's own words [7], for products to be accessible, 'the knowledge of users and other stakeholders needs to be fully taken into account in the design system because it is as important as maker's knowledge'. This approach is reflected in the rapid rise observed in the number of reception studies being conducted nowadays in AVT and MA [11]. Finally, the third shift distinguished by Greco [7] is characterised by a departure from retrofitting solutions to serve certain groups of users, where accessibility is merely an afterthought, towards a more encompassing and universal design approach [12-14] in which the needs of the various user groups are taken into consideration from the inception.

In this study, positioning ourselves within the paradigm of the second shift distinguished by Greco [7], we aim to bridge the gap between subtitle makers and subtitle users by gauging their views on subtitle quality, in order to find common ground to inform current subtitling practices. While the main goal of subtitling - both intra- and interlingual-is to foster access to multimedia content for all end users, its quality is often criticised for falling short of expectations and compromising the very access that it is supposed to enhance.
Quality is a slippery concept, notoriously difficult to define, pin down and measure. In the particular case of subtitling, it can be conceptualised from many angles, depending on the agents involved-be them policy makers, language service providers, researchers, professional subtitlers, subtitling trainers, viewers — on the dimension being scrutinisedlinguistic or technical. When it comes to gauging the quality of a set of subtitles, each of these groups of stakeholders, and ultimately each individual, tends to focus on different parameters or to assign them a different priority order. Admittedly, it will be simpler and less controversial to accept that there are several types of quality than to try and prescribe a unique, all-encompassing definition. Yet, to gain a holistic understanding of the elements that affect the perception of subtitling quality, the opinion of all the agents that take part in the creation and reception of subtitles-both makers and users alike - needs to be probed and taken into consideration.

This paper takes a novel approach by exploring subtitling quality as perceived by two dissimilar groups of stakeholders, i.e. professional subtitlers ('the makers') and viewers ('the end users'). This approach allows us to examine the most important quality indicators as seen by subtitle producers and end users. First, a review of various approaches to quality in translation in general, and in interlingual subtitling in particular, is offered. Then, we report on two qualitative studies: one based on an online survey conducted among professional subtitlers, and one based on semi-structured interviews with subtitle users. The paper outlines the most frequently raised issues pertaining to quality in subtitling and foregrounds the main convergences and discrepancies between these two important groups.

\section{Quality in translation}

Quality in translation can be approached from different angles. In the industry, quality is often viewed from the perspective of the process rather than the product [15]. This is, for instance, the case with norms such as ISO EN 17100:2015 on requirements for translation services, issued by the International Organization for Standardization, or the European quality standard for translation services EN 15038:2006, drafted by the European Committee for Standardisation. These norms specify the qualifications and competences of particular agents taking part in the translation workflow, including terminologists, translators, reviewers, proof-readers, revisers and managers. They also outline the actions to be taken by translation service providers at particular stages of the translation process. As such, they are largely focused on quality assurance and are mainly aimed at vendors and their clients.

In more academically oriented approaches, translation quality tends to be viewed from a non-normative 
perspective of linguistics and intercultural communication, where the focus is placed on equivalence, a term derived from the Latin aequus valere, i.e. 'equal value'. In academia, quality has been evaluated by resorting to translation models categorised under three main approaches: response-oriented, text-based and functionalpragmatic [16]. Response-oriented approaches, such as Nida's dynamic equivalence [17] and Gutt's relevancetheoretic model [18], aim to determine the response that a target text elicits from a given target audience, which ideally should be equivalent to the response induced by the source text in the original audience. Text-based approaches, largely rooted in linguistics, are concerned with comparing pairs of source and target texts to determine the various strategies used by the translator in terms of syntactic, semantic and stylistic shifts [16]. The functional-pragmatic model for translation quality assessment draws primarily on the intended function of the translation $[16,19,20]$.

While the assessment of quality in translated products has been particularly fruitful in the field of machine translation [21], where various quality metrics have been developed, including BLEU, NIST, METEOR and the more recent Multidimensional Quality Metrics [22], attempts to quantitatively measure quality in AVT have been rather scarce and mainly focused on access services. In the particular case of subtitling, the most popular model for quality assessment, both in the industry and in the academia, has probably been the NER (Number of words, Editions, Recognition) model, which is used in live intralingual subtitling done via respeaking [23-25]. Drawing on its predecessor, WER (Word Error Rate), which centred on the accuracy of the target text, the NER model allows for the calculation of the 'accuracy rate', which is a derivative of the number of idea units contained in the original dialogue on the one hand and the number of idea units found in the subtitle output on the other. The model also takes into account the number of edition and recognition errors made during the subtitling process, by judging their gravity, as well as their potentially disruptive impact on viewers' comprehension, whereby serious errors are penalised more severely than minor errors. The model also factors in omissions, which may be classified as correct editions when appropriate [26]. Subtitles need to reach an accuracy rate of at least $98 \%$ to be considered suitable for users.

A recent addition to the translation quality assessment family is the NTR (Number of words, Translation, Recognition) model, developed to assess quality in live interlingual subtitling done via respeaking [27]. The NTR model draws both on the NER model and on quality assessment paradigms applied in simultaneous interpreting [28].

\section{Quality in interlingual subtitling}

Quality in interlingual subtitling seems to be trickier to define and measure than it is for intralingual subtitling or interlingual textual translation, where, for instance, omissions are normally treated as errors. In interlingual subtitling, general models for the assessment of translation quality become insufficient for strategies like text reduction, condensation and omission, because they cannot always be categorised as errors, being part and parcel of the subtitling process $[1,29]$.

Grosso modo, the factors that have an impact on the quality of the subtitles that appear on screen can be grouped into three loose categories. Some of them are of a technical nature and therefore easily noticeable and closely linked with the spatial and temporal constraints imposed by the medium itself, such as synchronisation between text and soundtrack, subtitle display rate, observance of a minimum gap between chained subtitles, insufficient time to read a subtitle, respect of shot changes and sound bridges as well as adherence to the maximum number of characters allowed per line [30]. Most of these parameters can be easily monitored when working with software specifically designed for the creation of subtitles.

A second group of factors derive from the actual linguistic transfer, in which mishearings of the dialogue, excessive reduction in the original message, unorthodox line breaks, unwelcome presence of typos or infelicitous solutions that do not do justice to the source language or cultural reference can have a direct bearing on the quality of the subtitles. A mistake that can easily pass unnoticed in other translation contexts risks being easily spotted in a translation practice as uniquely vulnerable as subtitling [1], always challenged by the concomitant presence of the original dialogue exchanges.

In addition to these, other factors as important in determining the quality of the subtitled production relate to the working conditions under which professional subtitlers carry out their work, of which, as Fawcett [31] points out, '[t]he most important are: poor wages [...]; absurd deadlines $[\ldots]$; poor originals [...]; and finally, poor training of translators'. As a consequence, subtitlers might not have enough time to devote to the linguistic and cultural aspects of the translation of subtitles and to guarantee that all the technical aspects (e.g. cue in and out respecting shot changes, syntactical line breaks, etc.) are respected.

Despite its unsteady nature, or perhaps because of it, quality is an issue that has been assiduously investigated in subtitling since the late 1980s. In 1987, the first ever conference centred on dubbing and subtitling was organised in Stockholm under the auspices of the European Broadcasting Union (EBU). To boost the quality of the linguistic 
transfer, a proposal was put forward and approved by the EBU Television Programme Committee, to facilitate the international exchange, purchase and sale of television programmes [32]. Yet, the framework for action to implement these guidelines was rather limited as they were of a non-binding nature and focused almost exclusively on the need for the creation of detailed dialogue lists to accompany the programmes to be translated. Founded in 1995, the European Association for Studies in Screen Translation (ESIST) took upon itself the ambitious task of formulating and promoting a Code of Good Subtitling Practice, originally published by Ivarsson and Carroll [29], and freely available on the association's website [33].

Notwithstanding the inherent difficulties in defining and measuring the quality of interlingual subtitling, the reality is that this activity is routinely carried out in the AVT industry, drawing on quality assessment models articulated in the in-house style guides produced by different language service providers $[34,35]$ and that can also be found in certain textbooks $[1,29,36]$.

One of the early academic works to investigate both the theoretical and practical factors that may influence the quality of the subtitling output, as perceived by the professionals, is the one conducted by Kuo [37]. The scholar carried out two rounds of online surveys to elicit the working conditions of subtitlers around the world and thus gauge their impact on the quality of the resulting subtitles. From her qualitative study, she concluded that subtitling quality could be better enhanced if processes were streamlined, the quality of the support materials provided to subtitlers was improved, reasonable pecuniary rewards were offered to practitioners, and awareness of the importance of subtitling quality was raised among the various stakeholders, including the audience.

In view of the unique characteristics of interlingual subtitling, Pedersen [15] proposes the tripartite FAR model, in which he foregrounds functional equivalence, acceptability and readability as the three main pillars when it comes to quality. According to the scholar, functional equivalence prioritises communication, drawing largely on pragmatic equivalence since 'the actual words spoken are not as important as what you intend to get across' [2]. Acceptability, on the other hand, focuses on how well the translated text conforms to the norms of the target language and culture. The author contents that, ideally, the translation should be free of grammar, spelling and idiomatic errors. Finally, readability takes into account technical and layout aspects of subtitling, such as subtitle display rates, accurate spotting mindful of shot changes and sound bridges, respect of minimum gap between chained subtitles, judicious line breaks and correct punctuation. Deliberately focusing on subtitles as a product, Pedersen's model takes into consideration the impact that translation has on its users, and the severity of the errors is calculated based on how disruptive they are of the user experience [15, 25]. Similarly to the NER model, from which it heavily draws, the FAR model also assigns penalty points to each error.

In their study on quality control in the subtitling industry, Robert et al. [38] allocate importance to the translation process by distinguishing between quality management, quality assurance and quality control at three different stages, i.e. pre-translation, during translation and post-translation. The authors conducted an online survey among professional subtitlers and obtained data from 99 respondents on their role and contribution to the quality of interlingual subtitling. Subtitlers confessed to scrupulously follow the style guides given to them in terms of subtitle speeds, spotting and layout and admitted that, in their opinion, the most important parameters to affect quality were content, grammar, readability and contextual appropriateness.

As already stated, the present study is an attempt at ascertaining how quality in subtitling is perceived from two different viewpoints: production ('the makers') and reception ('the end users'). To this aim, we invited professional subtitlers (Study 1) and viewers (Study 2) to take part in a study, whose main goal was to elucidate the aspects that for them configure quality in subtitling. Given the current situation in the AVT industry, where a lot of interest has been laid on the reading of the subtitles, we decided to focus our attention on two quality parameters: subtitle display rates and line breaks. When it comes to subtitle display rates (also typically known as 'reading speed'), a pronounced rise in the speed at which subtitles are displayed on screen can be observed in recent years. Companies like TED and Netflix have moved on from the traditional rates of about 12 characters per second (cps) to much faster ones that can reach up to $20 \mathrm{cps}$, while at the same time allowing for longer lines containing a maximum of 42 characters, as opposed to previous values of 35,37 and 39 characters [34, 35]. Regarding line breaks, a cursory look at current subtitling practice evidences that conventional subtitling rules, which strongly recommend keeping semantic units together in one subtitle line [1, 29, 39-41], are not always adhered to in professional practice. Curious about the apparent contradictions of this state of affairs and its potential sustainability in the industry, we decided to embark on the investigation of how these two dimensions are perceived by two crucial stakeholder groups in subtitling.

\section{Study 1}

The study was articulated within a larger international project on the exploration of subtitle display rates and line breaks [42-45] and was undertaken at the Centre for Translation Studies (CenTraS) of University College London between 2016 and 2018 . 


\subsection{Methods}

As part of the study, we designed an online survey using Microsoft Forms (available as a supplementary file here), whose main goal was to elicit the opinion of professional subtitlers as far as subtitle display rates and line breaks were concerned [46]. The present paper reports on the final section of the questionnaire, where subtitlers were requested to offer their views on the parameters that influence quality in interlingual subtitling.

\subsubsection{Participants}

The survey was completed by 237 professional subtitlers from 27 different countries, both inside and outside of Europe. The survey consisted of closed-ended questions and one open-ended question. The open-ended question was completed by 220 participants. The largest groups of respondents came from countries with long-standing subtitling traditions, such as Finland (37), the Netherlands (36), Denmark (13), Norway (9) and Sweden (8). However, countries with dubbing and voiceover traditions like Spain (24), Poland (21), France (18) and Germany (5) were also reasonably well represented. Other participants came from Croatia (4), Italy (4), Slovenia (4), Belgium (3), Australia (2), Iran (2), Switzerland (2), and one from Argentina, Austria, Brazil, Canada, Greece, Israel, New Zealand, Slovakia and the USA.

As for their expertise, they were at various stages of their career, from very experienced to novices. They had been working in professional interlingual subtitling for periods ranging from 1 to 40 years, with the mean number of years of experience being 12.6 years $(S D=9)$. Most subtitlers work for local companies (118 people $=54 \%)$ or for both local and international companies ( 62 people $=28 \%$ ), while 40 people (18\%) declared to work mostly for international companies, as shown in Fig. 1.
Altogether, the professionals participating in this survey embody a large and varied sample of experienced subtitlers representing numerous parts of the world and different segments of the audiovisual translation market.

\subsubsection{Materials}

The survey was distributed online through subtitling organisations (AVTE, Subtle, ATRAE, Polish Association of Audiovisual Translators STAW), social media and personal networks. It consisted of 16 open- and close-ended questions (see the supplementary file), mostly focused on subtitle display rates and line breaks [46]. The last question, which was open-ended, aimed to elicit subtitlers' personal views on the quality of interlingual subtitling.

\subsection{Results and discussion}

The results of the survey were exported to Microsoft Excel. Using inductive coding [47], professional subtitlers' views on quality were analysed and grouped into the four most frequently recurring themes, namely: (1) invisibility of subtitles, (2) deterioration of quality, (3) higher display rates and less condensation, and (4) other issues. What follows is a detailed qualitative analysis of these themes.

\subsubsection{Invisibility of subtitles}

A central, frequently recurring theme reported by many subtitlers, particularly those from Scandinavian countries, was the idea that good subtitles are 'invisible', with one of the respondents resorting to the following trope: 'A good subtitle is like a pair of glasses. It helps you get the picture, but it doesn't distract in any way'. Some professionals strive to make their subtitles as 'invisible' as possible for, in their opinion, 'Good subtitles don't stand out on the screen'. The same idea is also picked up by other participants, who provided statements like:
Fig. 1 Types of companies subtitlers work for

\section{Which companies do you work for?}

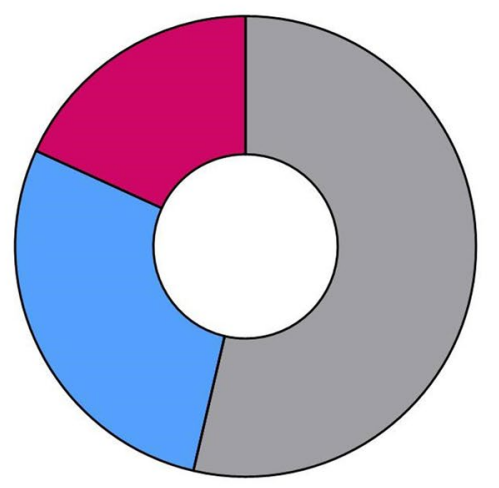

local companies

local and international companies international companies 
Good subtitles are those which you don't see. You read them without noticing them.

Subtitles are good when the viewer doesn't notice them.

Good subtitles are the ones you don't even notice, but afterwards you feel like you understood every word that was being said - in a language that you don't understand at all.

This opinion is reiterated by many others, who foreground the fact that viewers have to be able not only to read the subtitles but, more importantly, to follow the images too: 'Good subtitles should be close to invisible. They should be read easily and at a glance so one can enjoy the images'. In this respect, subtitles appear to be understood as subservient to the images and under no circumstances should they detract the viewers from watching and enjoying the visual content. How invisibility can be achieved in a practice based on the luminous projection and superimposition of fleeting text on moving images remains to be explained.

For most participants, all aspects of subtitling, whether linguistic, cultural or technical, need to coalesce in order to create good-quality subtitles, as intimated in the following quotes:

Good subtitles are [...] idiomatic and without misinterpretations and spelling errors.

Where the translation, dialogue flow, reading speed, nuances of language, etc. all form a synthesis that enhances the viewer's experience.

In their statements, subtitlers evince that they have thought of their viewers' needs and of the potential impact that the actual translation may have in their reading comprehension experience. Yet again, quantifying the success of some of the subtitle display rates or the transfer of certain linguistic nuances may prove more challenging than the above comments suggest. What seems to be clear from these assertions is the fact that the 'invisibility' of the subtitles continues to be a frequently reiterated theme in the profession. For instance, in his guidelines for Danish subtitlers, Lindberg states that ' $[\mathrm{g}] \mathrm{ood}$ subtitles are those you never notice' [48], while Díaz Cintas and Remael [1] also acknowledge the mantra that 'the best subtitles are those that the viewer does not notice' (p. 40). Interestingly, they also underline the inevitable contradiction that such a dictate entails as subtitlers are expected to produce an inconspicuous text which 'dashes in and out at the bottom of the screen' [1], while at the same time pretending that is not there. Indeed, rather than 'not being noticed', as this is clearly impossible because of the physical nature of subtitling and because viewers must see and read the subtitles if they are to understand the plot, what is usually implicit in these arguments is not so much the 'noticing' of the text on screen but the idea that subtitles should not perturb, in any way, the individual's reading experience, as explicated by this professional:

Good subtitles are clear and concise and easily understood. You could say that subtitles are best when they are in a sense invisible: the reading experience is so smooth that the viewer hardly notices she/he is reading.

On this point, it can be argued that subtitlers, the same as translators working in other fields, strive to make their texts as unobtrusive as possible in order to facilitate the reception of their message. Another long-held assumption in the profession is that bad-quality subtitles call undue attention to themselves, thus raising the viewers' suspicions about the worth of the translation and disrupting the reading experience-breaking what Pedersen [48] calls a 'contract of illusion' between subtitlers and viewers. Following this line of thought, it will be interesting to investigate whether unobtrusive but erroneous subtitles (i.e. incorrect translations or with grammatical errors in subtitles that do not distract the plot on screen) are better received by viewers than disruptive subtitles (i.e. subtitles that do not follow linguistic and technical guidelines) that are indeed more faithful to the content and intention of the original message.

\subsubsection{Deterioration of quality}

In the eyes of many professionals, the quality of subtitling has gone down in recent years [37]. According to the participants in the survey, the reasons for this tumble are multifarious and include the fall in rates, the rise in subtitle display rates, the widespread use of templates, the lack of quality control procedures and the influx of inexperienced people into the profession. This is aptly expressed by one experienced subtitler in the following terms:

The quality of subtitles is not as important as 15 years ago, unfortunately. Companies are paying less and less and do not hire proof-readers to save money. Companies are hiring young, unexperienced staff to get the work done cheaply. Since the introduction of templates, spotting is not as important as it used to be. I feel it's a downward spiral with more and more viewers complaining about bad quality. This can only be solved by introducing a minimum fee per subtitle.

Of all these reasons, the falling rates paid by some vendors is recurrently blamed by a substantive number of subtitlers as the major factor contributing to the drop in quality, as noted in the following quotes:

I think there are many subtitling companies nowadays which do not care enough about the quality of 
subtitles. They care more about making money. Rates for subtitlers are generally too low. This has a negative effect on the quality of subtitles.

The quality is going down fast, mainly because the world of subtitling/broadcasting is based on stinginess and greed. Networks, even the big ones [...] only care about money and have never given a toss about quality. My priority is quality, but that's becoming harder every day and I'm forced to find other work in the translation and/or language field.

Unfortunately, for many companies offering subtitling work at low rates is much more important than providing high quality.

A factor posited by some stakeholders in the industry highlights the detrimental impact of large subtitling multinationals in the domestic ecosystem:

The quality of subtitling in the Netherlands is dwindling fast because of the competition of international translation agencies, who seem to care very little for the income of their translators, who are usually freelancers.

The distribution medium is also a variable picked up by some subtitlers, who argue that different quality levels can be distinguished between subtitles that are broadcast on television and screened at the cinema, which generally tend to be of higher quality, and those published on DVDs, which are criticised for being less polished. Such observation is closely related to the previous reproach levelled at international companies, for these usually operate in the DVD industry:

In general, I find subtitle quality declining, especially in the DVD market and new media [...]. Poor Dutch translations, ridiculous reading speeds and lousy spotting.

DVD presentation times seem to be downright ridiculous today (too fast). Accompanied by illogical semantic breaks this contributes to significant deterioration in cohesion and viewer experience.

DVD subtitles seem to be of lower quality than the ones seen on TV and cinema, 'cause the DVD subtitlers are paid less and work with too tight schedules and with templates that simply should be banned (you can't fit different languages into the same format without making a poor outcome - sentence structures vary between languages so much that there's no point in using templates - the outcome is unnatural).

As illustrated in the last quote, professionals also voice their discontent with the use of templates. Introduced in the industry in the late 1990s because of the boom of the DVD and the need to manage new multilingual projects [49], a template is a list of master subtitles, with the in and out times already spotted, usually in the same language as the audiovisual production, and used as the starting point for the translation of the programme into as many languages as necessary. Although there are a number of advantages to using them as part of the subtitling workflow [50], their use has also been vilified by many professionals, as evidenced in the previous quote but also the following one:

Due to the severe drop in rates and the use of templates, reading speeds have become ever higher. Highly trained subtitlers are deemed too expensive, so people who have had little or no training now simply type Dutch words into English templates without much regard for reading speeds or quality.

Subtitlers in our study show awareness that using objective measures to determine the quality of subtitling is a rather challenging task, as subjectivity plays a significant role in the equation. It is thus often the case that stakeholders focus mainly on the technical aspects rather than on the translational ones, as the former tend to be easier to quantify and to spot, such as in the case of high display rates or asynchronous spotting:

Unfortunately, I find both my work place and the clients focus much more on the technical aspects of the subtitling (such as the maximum number of characters per second, technical preferences such as centre alignment, italics or no italics, raising, etc.) than on the actual translation. I work full time as a subtitler for a company with many clients, and I fill in a score card every week. It is sometimes frustrating that everyone seems to focus on the technical aspects, rather than the quality of one's work!

For another subtitler, measuring subtitling quality on the grounds of the technical, linguistic and cultural dimensions is insufficient, suggesting that quality should be observed in more holistic terms and accommodate other parameters, like working conditions:

The quality of subtitles must be seen in the context of the quality of the subtitled programme as a whole. In that sense, professional realities, academic assessments as well as subjective perceptions of what a good set of subtitles looks like must be taken into account.

\subsubsection{Higher display rates and less condensation}

Many survey takers are keen to stress that good-quality subtitles are characterised by a high degree of text condensation. Interestingly, this assumption in interlingual subtitling frontally clashes with the practice found in intralingual subtitling for the deaf and the hard-of-hearing, 
where heated debates are taking place on the issue and a clear tendency can be observed in favour of verbatim over condensed subtitles [51,52]. Traditionally, in interlingual subtitling, the need for text reduction and condensation has been incontestable and inescapable [1], as display rates of $12 \mathrm{cps}$ were pretty much the norm. Yet, new technical developments in the industry and the greater exposure of audiences to subtitles are having a direct impact in the increase in subtitles presentation speeds, that are going up to $17 \mathrm{cps}$, and the maximum number of characters allowed per line, extending on occasions to 42 , which in turn reflect less condensation of the target text. As highlighted by one Dutch subtitler:

Dutch subtitlers used to be very proud of their ability to condense. Recently, some of them tried to get the companies to allow more characters per line. They believed they could earn more money that way, but of course the art of subtitling degrades into the art of fast-typing.

This comment reflects the belief shared by many subtitlers that text condensation is part and parcel of the creative process of subtitling. In their opinion, increasing the display rates and the number of characters per line results in an unwelcome relaxation of the requirement to condense the text, thus leading to more literal translation. Although such an approach can shorten turnaround times and speed up the subtitling process, for many practitioners it also risks turning subtitling into 'the art of fast-typing', resulting in less creativity, a higher degree of literalness in the target text and, overall, lower quality of the subtitles.

For the respondents, the need to condense information in the subtitles, so as to avoid excessive subtitle display rates, is rooted in the conviction that apart from reading the subtitles, viewers also need to have enough time to follow the onscreen action, as foregrounded in these statements:

Good subtitling requires really processing the spoken text, because the viewer can't usually go back to check. The thought behind the words must be super clear, eloquently expressed, logically segmented and sufficiently concise to allow an unhurried presentation rate.

A quality translation gives the spectator enough time to also enjoy the pictures. You have to know and take the time to compress the message to its essence.

Subtitlers' reluctance towards verbatim translations is justified from a cognitive perspective, on the basis that high subtitle display rates can have a negative impact on the assimilation and enjoyment of the information transmitted through the images. This ensuing, imperative need for condensation brings about the necessity of finding creative solutions that, as theorised by Kovaćić [53], focus more on the intention and connotative meaning of the original dialogue than on its literal, denotative meaning. For many subtitlers, the crux of good subtitles resides in being able to master the type of linguistic creativity required to balance the losses incurred by the ubiquitous condensation:

Many subtitling translations are way too literal, resulting in gibberish Dutch, or in a text that may be a literal rendering of the dialogue spoken, but not of the intent behind the words.

I think that good subtitling is imaginative and makes good use of the possibilities that the target language offers. It neither can nor should follow the original too rigidly, because this tends to kill style and beauty and lead to empty, albeit perhaps formally correct, translations.

In a similar vein, one subtitler explains:

We focus even more on getting the *meaning* across, even if we often can't translate very literally because of the time restraint. So, to me (and many Danish subtitlers), good subtitles get the meaning of the dialogue across to the viewer; not only *what* is being said, but also *how* it is being said.

One of the participants goes even further and claims that non-condensed subtitles are the result of work done by people with little professional experience, who are afraid of departing too much from the original configuration:

Some subtitles are poorly done, obviously work of amateurs, when there is too much content and there is not enough time to read and poor cueing. Good subtitles should be concise.

Others establish a straightforward and logical parallel between the lower degree of text condensation observed these days and the increase in subtitle display rates and line lengths. Indeed, the higher the presentation rate and the extension of the lines, the more text can be fitted in the subtitles. For some respondents, as already discussed, the hike in presentation rates and the lower levels of condensation stem from the widespread use of English templates in the industry, as decried by this professional:

I think reading speed is a very important factor in determining subtitle quality. I sometimes get subtitle files that have been done elsewhere based on an English template file and these subtitles invariably have far too high reading speeds of 18 to (in some cases) over $30 \mathrm{cps}$ ! When people complain about poor subtitles, they tend to come up with examples of bad translations but when I watch DVDs that have poor subtitles, the main problem is usually that the subtitles aren't condensed enough, with literal translations 
leading to absurd reading speeds, which means you can no longer watch the programme since you're just reading the subtitles.

\subsubsection{Other issues}

Other issues raised by subtitlers include the lack of proper recognition of subtitling as a profession and the little awareness of the complexity surrounding the linguistic, cultural and technical dimensions that characterise the process of subtitling. The former is one of the contributing factors to the falling rates being paid for subtitling and to the outflow of experienced subtitlers from the profession. The latter often results in misunderstandings between the client/vendor and the subtitler or in errors being made by novice subtitlers. To overcome these challenges, closer collaboration and more fluid dialogue should be facilitated across all subtitling stakeholders, including professional associations, academia, practitioners, clients, audiovisual translation vendors and the general public, so that awareness on subtitling and audiovisual translation can be raised in society.

\section{Study 2}

Study 2 was part of a larger research project focused on subtitling speeds and line breaks, where viewers with different audiovisual habits were shown subtitled videos and asked to answer a number of questions while their gaze was monitored with an eye tracker. A detailed description of the eye tracking experiment and the quantitative results are reported elsewhere $[44,54]$. The emphasis on these pages is placed on the results obtained from semi-structured interviews conducted after the eye-tracking tests, relating to the quality of subtitling as perceived by viewers.

\subsection{Methods}

The study took place at University College London, where it received full ethical approval from the university's Research Ethics Committee. On average, the test took approximately 90 min per person, depending on the time taken by the participant to answer the various questions. Each respondent was rewarded with $£ 10$ for taking part in the study.

\subsubsection{Participants}

Participants were recruited through the UCL Psychology subject pool, personal networking and social media. A total of 74 hearing native speakers of English (27), Polish

\section{Participants by mother tongue}

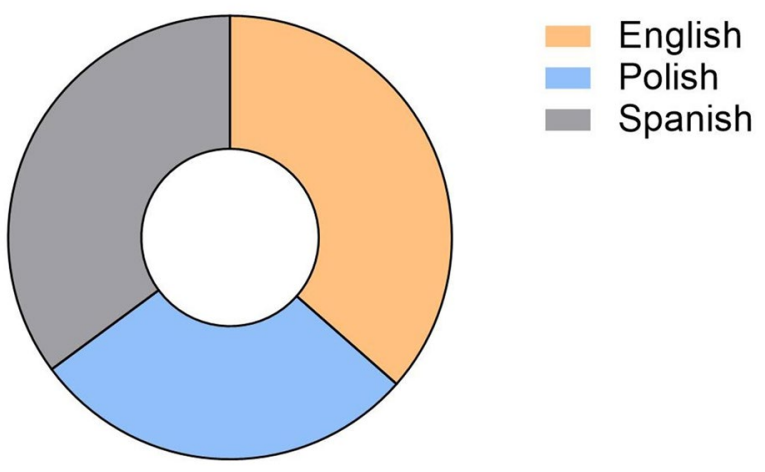

Fig. 2 Breakdown of study participants by mother tongue

(21) and Spanish (26) took part in the experiment, as illustrated in Fig. 2.

Participants' ages ranged from 19 to $54(M=26.55$, $S D=5.86)$. Among the English speakers, 13 were male and 14 female; among the Polish, 5 were male and 16 female; and among the Spanish, 10 were male and 16 were female.

At the participant selection stage, we wanted to recruit people with varying experience of different types of AVT. We expected that the country of origin would somewhat dictate the participants' preference for a particular type of audiovisual translation, be it dubbing (Spanish), subtitling (English) or voiceover (Polish). In this sense, for instance, it was assumed that Spanish people would favour dubbing over the other modes. However, when asked about their preferred type of audiovisual translation, as displayed in Fig. 3, the vast majority selected subtitling (77\%). Only $2 \%$ of the respondents opted for dubbing, $1 \%$ went for voiceover and $19 \%$ claimed to enjoy foreign programmes in their original version, without any translation. $1 \%$ declared not to watch films in other languages.

Per language group, 24 English participants chose subtitling, one selected dubbing, one favoured voiceover and another one admitted to not watching foreign films. In the case of the Polish cohort, 11 participants declared to prefer subtitling, while 10 people stated that they watch films in the original English version, with no translation at all. Among the Spanish respondents, 22 affirmed their preference for subtitling, one person chose dubbing and three of them commented that they watch films in the original language. This apparent enthusiasm to watch films in their original version may be attributed to some of the changes witnessed in the AVT landscape in recent years [55], including the possibility offered to consumers to choose their preferred type of AVT. Thanks to novel technological solutions, Spanish viewers are no longer obliged to watch films with 
Fig. 3 Overall breakout of participants' preferred type of audiovisual translation

\section{Participants' preferred AVT type}

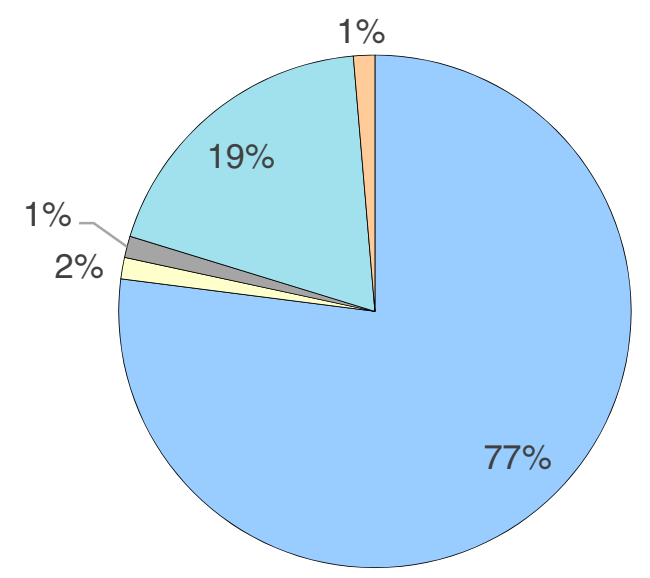

$\square$ Subtitling

$\square$ Dubbing

$\square$ Voice-over

$\square$ Original English version

$\square$ I don't watch foreign films

\section{Participants' proficiency in English}

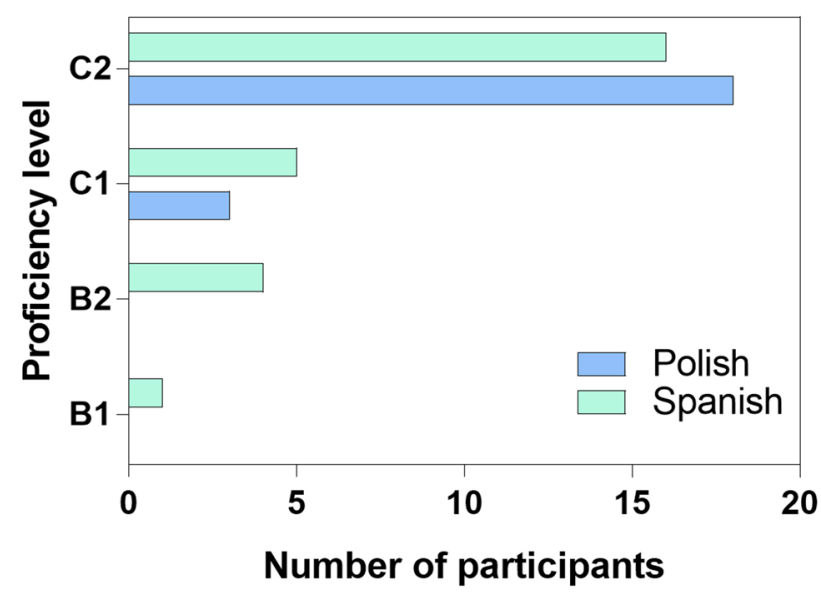

Fig. 4 Participants' level of proficiency in English

dubbing only, just as Polish viewers have more options than voiceover at their disposal. Another factor impinging on this situation is the fact that the participants were living in the UK at the time of the experiment.

Because some of the testing material in the study was shown with English audio (see Sect. 5.1.2), Polish and Spanish nationals were asked to self-report their level of proficiency in English, using special charts from the Common European Framework of Reference for Languages.

As shown in Fig. 4, Polish people felt more confident in their grasp of the English language. Of the 47 participants, most of them (89\%) claimed high proficiency in English, whether C2 (72\%) or C1 (17\%). Only 5 Spaniards (11\%) considered their knowledge of English to be intermediate (1 person declared B1 level and 4 people B2) and no participants declared a level lower than B1.

\subsubsection{Procedure}

Participants were tested individually in a research laboratory at UCL and, before the actual experiment, were informed that they would take part in a study on the quality of subtitles. After signing the informed consent form, participants were shown a set of clips in a language they were unfamiliar with (Hungarian) and another set in English. The clips were either subtitled interlingually into the participants' mother tongue (Spanish for Spanish speakers, Polish for Polish speakers, English for English speakers) or displayed with Englishto-English intralingual subtitles; they were presented at different speeds and following different line breaks [43-45, 54]. For full information on experiment design, clips and variables, see the Sure Project Dataset [42]. Finally, the participants' views on subtitling quality were elicited in semi-structured interviews.

\subsubsection{Interview}

At the beginning of the interview, participants were queried about their preferred AVT mode and encouraged to share their prior exposure to subtitling with the researchers. Since they were all living in the UK when the study was conducted, they were also asked whether their views on subtitling had changed since their arrival in the country. These introductory questions were followed up by a battery of subtitling-related questions, divided into three parts: (1) subtitle display rates, (2) line breaks and (3) subtitling quality. In the interview, participants were encouraged not only to comment on the subtitles they had watched during the experiment but also to offer their general opinion on this translation practice. They were specifically asked about the main features that, in their view, constitute ideal subtitles. 


\subsection{Results and discussion}

In a similar fashion as in Study 1, participants' responses were grouped according to the three most frequently occurring themes, namely: (1) accuracy of the subtitles, (2) technical synchronisation and (3) other issues.

\subsubsection{Accuracy of the subtitles}

When questioned about what constitutes good-quality subtitles for them, many participants mentioned the 'accuracy' of the subtitles. Prompted to elaborate on what they meant by accuracy, they tended to refer to the affinity/ discrepancy they could establish between the content of the subtitles and the soundtrack (in the case of clips with the English audio). These comparisons focused mostly on the original information that appeared to be missing in the subtitles and which led most respondents to reflect on the degree of closeness that should (or should not) exist between the spoken dialogue exchanges and the written subtitles. Some viewers expressed the opinion that the text in the subtitles should be as close to the original dialogue as possible:

I would love to have as much text as possible because I know sometimes the subtitles just say the gist of it, like really basic... I would prefer the full text just in case, 'cause I don't mind if I'm missing anything, if they really, really explain the whole situation. From a personal point of view, I would get more out of it. The full written dialogue is preferred, yet when you're tired perhaps a short version could do. Maybe on DVDs it would be an option that could be offered.

Yet, this level of completeness is questioned by some of the respondents, who fear that too much text may have negative implications from an aesthetics point of view:

I think I like it halfway, sort of a mixture of both, because if you put too much it covers too much of the screen and you're not seeing the action on the film, but if you put too little you're missing what's the actual subject you're talking about, you know, if that makes sense?

When discussing films and programmes in English, respondents raised the issue of perceived incongruities between the dialogue and the subtitles, claiming that these mismatches can lead to a feeling of annoyance during the film viewing process:

They annoyed me because the subtitles didn't match the original dialogue, so it felt there was a conflict when I was reading the subtitles. And it was just that it annoyed me so much that I stopped and I didn't enjoy it, unless I was watching without the subtitles.

Some participants expressed the view that the level of text condensation in subtitling should depend on the degree of familiarity of the viewers with the foreign language used in the original soundtrack, whereby greater acquaintance with the foreign tongue should command denser subtitles:

When I'm watching something I understand I'd like to be able to read exactly what I'm hearing, and when I'm watching something that I don't understand I prefer there to be minimal words in the subtitles so that I can get a gist of what's being said and still be able to follow the scenes of the movie.

Those viewers who professed a preference for a fuller version of the subtitles did so because, in their opinion, if subtitles are condensed, some of the nuances and subtleties or the original dialogue are irremediably lost:

I prefer as much dialogue as possible because when you subtitle things that are in different languages you get loads of dialogue overlapping, and the thing about it being in a foreign language is I can't guess what might be said if it's not there. So, I feel it's better to have as much information as possible.

A different view supporting the condensation of dialogue in the target subtitles was expressed by a few people, who, in a similar fashion as the subtitlers surveyed in the first study, declare a predilection for short subtitles that contain the gist of the message:

I don't think it's important to follow exactly what's being said on the screen. I think it's better to be more... sparky and pointy and actually reduce the number of words to make the visual experience more appealing. The snappier it is, the better.

Condensed and edited: because obviously you need to read the subtitle and look at the screen to get a sense of what's going on as you read the title, otherwise it just becomes really tiring. So, I prefer to just get the essence of the conversation.

As in Study 1, some viewers commented that the degree of text condensation is directly connected with the display rate of the subtitles, with higher speeds making it more difficult for some viewers to be able to finish reading the subtitle while at the same time following the images and the film narrative:

I find it most irritating when I can't finish the subtitle, and it usually happens with the subtitles like fan made or something, where they put all the text that you can hear and it's not necessary in my 
opinion, usually. So, I prefer when there is less text but you can comfortably read all of the subtitles.

Unsurprisingly, fast subtitles are particularly problematic for viewers who are slow readers:

I want subtitles that are slow enough so that I can read them [...] I want to be able to read the subtitles so I understand the dialogue, however I wouldn't want the subtitles to be so simplified that I'm missing half the information that's been given in the original dialogue, and it's tricky. I suppose what's most important is that I get the gist of what's going on in the scene, so if I' $m$ missing a lot of the subtitles because they're going by too quickly then no, I would want it slowed down, but, I mean, I really would also want as much of the original dialogue in there as possible [...] because I kind of want it all.

Interestingly, when compared with intralingual Englishto-English subtitles commonly used for pedagogical purposes [56-58], a number of non-English native speakers expressed a negative opinion of the standard interlingual subtitling done in their mother tongue. Indeed, some Polish and Spanish participants confessed that, when watching English audiovisual productions, they prefer to watch them with English rather than Spanish/Polish subtitles, as they consider them to be more 'accurate'. Their rationale behind this preference is that whereas English-to-Polish or Englishto-Spanish subtitles are condensed and some original information is omitted, English-to-English subtitles contain a fuller version of the source dialogue, which viewers find useful for language learning purposes. Of course, it should be born in mind that the participants are not be fully representative of their native populations, as they were individuals who had chosen to move to the UK and were not only better at English but possibly also more Anglo-friendly than their compatriots back home.

\subsubsection{Technical synchronisation}

When asked about the features that make an ideal subtitle, most participants mentioned synchronisation. As they were not subtitling professionals, most of them did not use the term per se, but instead they talked about the 'timing' of the subtitles and the subtitles being 'in sync'. In this respect, they stressed the fact that subtitles should be synchronised with the soundtrack and appear in sync with the dialogue exchanges that can be heard on screen, as well as with the images. The need for accurate synchrony between subs and soundtrack was attributed to the educational value of the subtitles, as when this technical dimension is well accomplished both the original text and its translation are concurrent, thus helping those interested to learn grammar and new vocabulary.

According to one viewer, the issue of timing is particularly important in comedies, when subtitles should appear in perfect sync with the dialogue so that the comedic effect is triggered at the same time in the original and the translated versions:

This is where I think subtitling is most difficult because so much of comedy is in the timing. It's not as much what is said but it's how it's said and it's when it's said, and that, like that's why comedy is such a talent. There are people who just have such brilliant natural comic delivery, and I would say it's impossible to recreate that in subtitling [...], and if the punch line is actually ahead of the joke it's even a bit off-putting, I think.

\subsubsection{Other issues}

Contrary to our initial expectations, many participants did not think that syntactically driven line breaks are very important in subtitling, as summarised by this person's affirmation:

Line breaks have their value, yet when you are reading fast most of the time it becomes less relevant.

A number of participants suggested that subtitling priorities and conventions should vary depending on the genre of the audiovisual production being translated, stressing that certain solutions may be appropriate for some genres but not for others. For instance, when it comes to the strategy of condensation, one of the respondents opines that, although common in the subtitling of feature films, this strategy should be scarcely used when dealing with documentaries that contain factual information:

It depends on the type of movie you're watching. If I watch a nature documentary, I definitely prefer longer subtitles because I want all the details [...] and I think they should also be adjusted to the pace of the movie.

As for the invisibility of the subtitles, and contrary to the importance given to this factor by professional subtitlers, only one of the viewers picked on it, agreeing on the fact that good subtitles should be invisible, and confirming that only when they are of poor quality do viewers notice them, as they disrupt the reading experience:

I think when subtitles are good you don't think about it at all, you just read them. So, I think the measure of good subtitles is when you don't really think about it at all, you just take in what's being said.

It is possible that invisibility was not brought up as an important topic for viewers because, from their perspective, 
subtitles are often erroneous and disruptive. Invisibility may also be considered more during the creation of subtitles rather than their reception; hence, it pertains more to the subtitlers than viewers.

\section{Discussion and conclusion}

Having elicited the views of both groups, subtitling professionals and viewers, some convergences as well as discrepancies can be observed in the way in which they judge the concept of quality in subtitling.

Quality is considered an important aspect of subtitling by the two sets of participants. They also agree that goodquality subtitles are those that allow viewers to understand the plot while comfortably following the onscreen action, without drawing unwarranted attention to themselves. In contrast, poor-quality subtitles are believed to break the fictional contract of illusion [48] and the suspension of disbelief [59], thus lowering the viewers' enjoyment and feeling of immersion in the film diegesis. Particularly, viewers are more prone to notice the presence of subtitles on screen when they are more difficult to read, be it because of their linguistic or technical inconsistencies. As a result, and when subtitling from English, poor-quality subtitles in the target language risk leading some viewers to consciously stop reading them, to switch them off altogether, or to change their mind and watch intralingual English-to-English subtitles instead.

While, as expected, both subtitlers and viewers agree that quality is important, they sometimes differ quite substantially in what they think the hallmark of goodquality subtitles is. The most pronounced discrepancy in the perception of quality in our study relates to the strategy of text condensation. While professionals consistently equate good-quality subtitles with a high degree of text condensation, many viewers complain that not all the information contained in the original dialogue makes it to the subtitles, leaving them confused and perplexed as they can hear one thing but find themselves reading something else. They admit, however, that the missing information is not always crucial for the understanding of the plot, for it tends to be somewhat marginal and its objective is to contribute to the nuanced depiction of the characters, their use of certain linguistic idiosyncrasies and their sense of humour. This finding is inextricably linked to the viewers' proficiency in the original language of the audiovisual production. Indeed, condensation is perceived as a sign of poor quality in Spanish and Polish subtitles of original versions in English, a language with which participants were familiar. Respondents claim that when watching English-spoken clips, they often use subtitles in their mother tongue as a backup plan, to reconfirm the information that they can hear in the soundtrack. Conversely, when confronted with clips shot in a distant language with which they were not acquaintedHungarian in our experiment-instances of condensation in the target subtitles were not perceived as negative. To sum up, viewers' knowledge of the original language is a decisive factor in their acceptance or refusal of the condensation strategy.

In spite of the recommendations put forward in numerous subtitling protocols, advocating close collaboration between all the agents involved in the translation and revision workflow, the professional reality seems to be somewhat different. Most practitioners appear to conceptualise subtitling from a product viewpoint rather than from a processual one. So, even though on occasions they think of themselves as the metaphorical $\operatorname{cog}$ s in a bigger subtitle production machinery, they ultimately fail to feel that they are an integrated part of a larger team, working towards a common goal. Instead, they tend to express their opinions from a rather individualistic perspective, frequently positioning themselves in manifest opposition to language service providers and media localisation companies; an attitude that can be easily explained because of the isolated, freelancing status of most professionals working in the industry.

None of the practitioners that took part in the study ever mentioned any translation quality assessment models. The reasons for this may be manifold. It is quite likely that they are simply not familiar with any of these theoretical models and, even if they do, they may not find them relevant to their daily work. Another reason could be that they actually implement these models in their work without being fully conscious that they are doing so, be it because they have internalised them over their years of practice or because they have been trained on them without having been explicitly informed. Whatever the reasons for this state of affairs, the reality is that translation quality models do not seem to occupy a distinct space in the subtitlers' working environment. On the contrary, the commissioner's style guides are systematically referred to by most professionals as their key reference document to achieve high-quality levels.

In contrast to professional subtitlers, viewers are often unaware of the technical limitations involved in the creation of subtitles or the type of challenges that subtitlers have to face, such as impossibly tight deadlines, falling rates or the spread of English templates. While viewers often complain about the poor quality of the subtitles they watch, usually because of high levels of textual condensation, they may not realise that such a strategy may be a necessary one when subtitling certain scenes in films and TV series in which the characters speak fast. One of the suggestions of this study is that viewers need to be made aware of the multiple intricacies and technical limitations that typify subtitling. 
In this respect, AVT associations, in collaboration with educational centres, could play a pivotal role in increasing the social visibility of subtitling as a profession. Educating new clients and commissioners on the defining features of good-quality subtitling is another line of action that could prove fruitful and that is already being pursued by initiatives like accessible filmmaking, postulated by scholars like Romero Fresco [60, 61].

In this paper, we have only focused on the views expressed by professional subtitlers and viewers. Future studies could probe the opinion of other stakeholders in the subtitling process, such as language service providers, subtitling trainers, media entertainment companies, digital content producers and online content distributors. Nowadays, commercial and amateur subtitling produced by fansubbers or found on some internet platforms like TED show distinct qualitative differences at linguistic, cultural and technical levels, with some consumers of fansubbing happy to sacrifice the quality of the subtitles in favour of the speed at which the programmes are made available on internet [62]. Likewise, the irruption of machine translation in commercial subtitling is impacting on the potential quality offered to the client, who can choose between raw automated subtitles or subtitles that have gone through either a light or in-depth post-editing process, depending on the client's needs and requirements. Without a doubt, subtitling is here to stay and to metamorphose as technology evolves and viewers' exposure increases.

Acknowledgements The research reported here has been supported by a grant from the European Union's Horizon 2020 research and innovation programme under the Marie Skłodowska-Curie Grant Agreement No. 702606 and from 'La Caixa' Foundation (E-08-2014-1306365) and Transmedia Catalonia Research Group (2017SGR/113).

Open Access This article is licensed under a Creative Commons Attribution 4.0 International License, which permits use, sharing, adaptation, distribution and reproduction in any medium or format, as long as you give appropriate credit to the original author(s) and the source, provide a link to the Creative Commons licence, and indicate if changes were made. The images or other third party material in this article are included in the article's Creative Commons licence, unless indicated otherwise in a credit line to the material. If material is not included in the article's Creative Commons licence and your intended use is not permitted by statutory regulation or exceeds the permitted use, you will need to obtain permission directly from the copyright holder. To view a copy of this licence, visit http://creativecommons .org/licenses/by/4.0/.

\section{References}

1. Díaz Cintas, J., Remael, A.: Audiovisual Translation: Subtitling. St. Jerome, Manchester (2007)

2. Neves, J.: Ten fallacies about subtitling for the $\mathrm{d} / \mathrm{deaf}$ and the hard of hearing. J. Spec. Transl. 10, 128-143 (2008)
3. Neves, J.: Subtitling for deaf and hard of hearing audiences. In: Pérez-González, L. (ed.) The Routledge Handbook of Audiovisual Translation, pp. 82-95. Routledge, London (2018). https://doi. org/10.4324/9781315717166-6

4. Szarkowska, A.: Towards interlingual subtitling for the deaf and the hard of hearing. Perspectives 21(1), 68-81 (2013). https://doi. org/10.1080/0907676X.2012.722650

5. Robson, G.D.: The Closed Captioning Handbook. Focal Press, Burlington (2004)

6. Downey, G.J.: Closed Captioning: Subtitling, Stenography, and the Digital Convergence of Text with Television. Johns Hopkins University Press, Baltimore (2008)

7. Greco, G.M.: The nature of accessibility studies. J. Audiov. Transl. 1(1), 205-232 (2018)

8. Díaz Cintas, J.: Audiovisual translation today-a question of accessibility for all. Transl. Today 4, 3-5 (2005)

9. Greco, G.M., Paronitti, G., Turilli, M., Floridi, L.: How to do philosophy informationally. Prof. Knowl. Manag. 3782, 623-634 (2005)

10. Thompson, T.: The interdependent roles of all players in making technology accessible. J. Spec. Educ. Technol 18(4), 21-27 (2003). https://doi.org/10.1177/016264340301800402

11. Di Giovanni, E., Gambier, Y.: Reception Studies and Audiovisual Translation. John Benjamins, Amsterdam (2018)

12. Szarkowska, A., Jankowska, A., Kowalski, J., Krejtz, K.: Open art: designing accessible content in a multimedia guide app for visitors with and without sensory impairments. In: Matamala, A., Orero Clavero, P. (eds.) Researching Audio Description: New Approaches, pp. 301-320. Palgrave Macmillan, London (2016)

13. Jankowska, A., Szarkowska, A., Krejtz, K., Fidyka, A., Kowalski, J., Wichrowski, M.: Smartphone app as a museum guide. Testing the Open Art application with blind, deaf, and sighted users. IJT 19, 113-130 (2017). https://doi.org/10.13137/2421-6763/17354

14. Vanderheiden, G.C.: Universal design and assistive technology in communication and information technologies: alternatives or complements? Assist. Technol. 10(1), 29 (1998). https://doi. org/10.1080/10400435.1998.10131958

15. Pedersen, J.: The FAR model: assessing quality in interlingual subtitling. J. Spec. Transl. 28, 210-229 (2017)

16. House, J.: Quality. In: Baker, M., Saldanha, G. (eds.) Routledge Encyclopedia of Translation Studies, pp. 222-225. Routledge, London (2009)

17. Nida, E.: Towards a Science of Translating. E. J Brill, Leiden (1964)

18. Gutt, E.-A.: Translation and Relevance: Cognition and Context, 2nd edn. St Jerome, Manchester (2014)

19. House, J.: Quality in translation studies. In: Millán, C., Bartrina, F. (eds.) The Routledge Handbook of Translation Studies, pp. 534547. Routledge, London (2013). https://doi.org/10.4324/97802 03102893.ch39

20. House, J.: Translation Quality Assessment: Past and Present. Routledge, London (2015)

21. Burchardt, A., Lommel, A., Bywood, L., Harris, K., Popović, M.: Machine translation quality in an audiovisual context. Target 28(2), 206-221 (2016). https://doi.org/10.1075/target.28.2.03bur

22. Lommel, A., Uszkoreit, H., Burchardt, A.: Multidimensional quality metrics (MQM): a framework for declaring and describing translation quality metrics. Revista tradumàtica: traducció i tecnologies de la informació i la comunicació 12, 455-463 (2014)

23. Ofcom (2014) Measuring live subtitling quality. Results from the first sampling exercise.

24. Ofcom (2015) Measuring live subtitling quality. Results from the fourth sampling exercise.

25. Romero-Fresco, P.: Accessing communication: the quality of live subtitles in the UK. Lang. Commun. 49, 56-69 (2016). https://doi. org/10.1016/j.langcom.2016.06.001 
26. Romero-Fresco, P., Martínez, J.: Accuracy rate in live subtitling: the NER model. In: Díaz-Cintas, J., Baños Piñero, R. (eds.) Audiovisual Translation in a Global Context. Mapping an Everchanging Landscape, pp. 28-50. Palgrave, London (2015)

27. Romero-Fresco, P., Pöchhacker, F.: Quality assessment in interlingual live subtitling: the NTR model. Linguist Antverp New Ser 16, 149-167 (2017)

28. Pöchhacker, F.: Quality assurance in simultaneous interpreting. In: Dollerup, C., Lindegaard, A. (eds.) Teaching Translation and Interpreting 2: Insights, Aims, Visions: Papers from the Second Language International Conference, pp. 233-242. John Benjamins, Amsterdam (1994)

29. Ivarsson, J., Carroll, M.: Subtitling. TransEdit HB, Simrishamn (1998)

30. Wildblood, A.: A subtitle is not a translation: a day in the life of a subtitler. Lang. Int. 14(2), 40-43 (2002)

31. Fawcett, P.: Translation modes and constraints. Inc. Linguist 22(4), 186-190 (1983)

32. Ivarsson, J.: Subtitling for the Media. TransEdit HB, Stockholm (1992)

33. ESIST (1998) Code of Good Subtitling Practice

34. Netflix (2016) Timed Text Style Guide: General Requirements

35. TED (2017) English Style Guide. https://translations.ted.org/wiki/ English_Style_Guide. Accessed 3 July 2020

36. Belczyk, A.: Tłumaczenie filmów (Translating Films). Wydawnictwo Dla Szkoły, Wilkowice (2007)

37. Kuo, S.-Y.: Quality in subtitling: theory and professional reality. Ph.D., Imperial College London, London (2014)

38. Robert, I.S., Remael, A., Bastin, G.L.: Quality control in the subtitling industry: an exploratory survey study. Meta 61(3), 578-605 (2016)

39. BBC (2017) BBC Subtitle Guidelines.

40. Karamitroglou, F.: A proposed set of subtitling standards in Europe. Transl. J. (1998). http://www.translationjournal.net/journ al/04stndrd.htm. Accessed 2 July 2020

41. Ofcom (2015) Ofcom's code on television access services

42. Szarkowska, A., Gerber-Morón, O.: SURE project dataset (trans: Commission E). RepOD (2018). https://doi.org/10.18150/repod .4469278

43. Gerber-Morón, O., Szarkowska, A.: Line breaks in subtitling: an eye tracking study on viewer preferences. J. Eye Mov. Res. 11(3), 1-22 (2018)

44. Szarkowska, A., Gerber-Morón, O.: Viewers can keep up with fast subtitles: evidence from eye movements. PLoS ONE (2018). https ://doi.org/10.1371/journal.pone.0199331

45. Szarkowska, A., Gerber-Morón, O.: Two or three lines: a mixedmethods study on subtitle processing and preferences. Perspectives 27(1), 144-164 (2019). https://doi.org/10.1080/09076 76x.2018.1520267

46. Szarkowska, A.: Report on the Results of an Online Survey on Subtitle Presentation Times and Line Breaks in Interlingual Subtitling. Part 1: Subtitlers. University College London, London (2016)

47. Bazeley, P.: Qualitative Data Analysis. Practical Strategies. Sage, London (2013)
48. Pedersen, J.: Subtitling Norms for Television: An Exploration Focussing on Extralinguistic Cultural References. John Benjamins, Amsterdam (2011)

49. Georgakopoulou, P.: Challenges for the Audiovisual Industry in the Digital Age: The Ever-changing Needs of Subtitling Production. J. Spec. Transl. 17, 78-103 (2012)

50. Nikolić, K.: The pros and cons of using templates in subtitling. In: Baños Piñero, R., Díaz-Cintas, J. (eds.) Audiovisual Translation in a Global Context. Mapping and Ever-changing Landscape, pp. 192-202. Palgrave, Macmillan, Basingstoke (2015)

51. Szarkowska, A., Krejtz, I., Kłyszejko, Z., Wieczorek, A.: Verbatim, standard, or edited? Reading patterns of different captioning styles among deaf, hard of hearing, and hearing viewers. Am. Ann. Deaf 156(4), 363-378 (2011)

52. Szarkowska, A., Krejtz, I., Pilipczuk, O., Dutka, Ł., Kruger, J.-L.: The effects of text editing and subtitle presentation rate on the comprehension and reading patterns of interlingual and intralingual subtitles among deaf, hard of hearing and hearing viewers. Across Lang. Cult. 17(2), 183-204 (2016). https://doi. org/10.1556/084.2016.17.2.3

53. Kovaćić, I.: Relevance as a factor in subtitling reductions. In: Dollerup, C., Lindegaard, A. (eds.) Teaching Translation and Interpreting 2, pp. 245-251. John Benjamins, Amsterdam (1994)

54. Gerber-Morón, O., Szarkowska, A., Woll, B.: The impact of text segmentation on subtitle reading. J. Eye Mov. Res. 11(4), 1-18 (2018). https://doi.org/10.16910/jemr.11.4.2

55. Matamala, A., Perego, E., Bottiroli, S.: Dubbing versus subtitling yet again? Babel 63(3), 423-441 (2017). https://doi.org/10.1075/ babel.63.3.07mat

56. Díaz Cintas, J.: The Didactics of Audiovisual Translation. John Benjamins, Amsterdam (2008)

57. Vanderplank, R.: Captioned Media in Foreign Language Learning and Teaching: Subtitles for the Deaf and Hard-of-Hearing as Tools for Language Learning. Palgrave Macmillan, London (2016)

58. Incalcaterra Mcloughlin, L., Biscio, M., Ní Mhainnín, M.Á.: Audiovisual Translation-Subtitles and Subtitling: Theory and Practice. Peter Lang, Oxford (2011)

59. Chandler, D., Munday, R.: Suspension of Disbelief. A Dictionary of Media and Communication, 2nd edn. Oxford University Press, Oxford (2016)

60. Romero-Fresco, P.: Accessible filmmaking: joining the dots between audiovisual translation, accessibility and filmmaking. J. Spec. Transl. 20, 201-223 (2013)

61. Romero-Fresco, P.: Accessible Filmmaking: Integrating Translation and Accessibility into the Filmmaking Process. Routledge, London (2019)

62. Massidda, S.: Audiovisual Translation in the Digital Age: The Italian Fansubbing Phenomenon. Palgrave Macmillan, Basingstoke (2015). https://doi.org/10.1057/9781137470379

Publisher's Note Springer Nature remains neutral with regard to jurisdictional claims in published maps and institutional affiliations. 